\title{
Public versus Private Education when Differential Fertility Matters*
}

\author{
David de la Croix \\ FNRS, IRES, and CORE
}

\author{
Matthias Doepke \\ UCLA
}

April 2003

\begin{abstract}
We assess the merits of different education systems in a framework that accounts for the joint decision problem of parents regarding fertility and education. Specifically, we compare the implications of a public and a private schooling regime for economic growth and inequality. We find that private schooling leads to higher growth when there is little inequality in human capital endowments across families. In contrast, when inequality is high, public education yields higher growth by reducing fertility differentials. In addition, public schooling leads to income convergence, while private schooling can result in ever increasing inequality. Our analysis highlights the importance of accounting for endogenous fertility differentials when analyzing educational policies.
\end{abstract}

JEL Classification: I20, J13, O15, O40

Keywords: Education, human capital, growth, fertility, inequality

*We thank Pierre Devillé, Maurice Marchand, Philippe Pestieau, and two anonymous referees for their comments on an earlier draft. David de la Croix acknowledges the financial support of the Belgian French-speaking community (Grant ARC 99/04-235 "Growth and incentive design") and of the Belgian Federal Government (Grant PAI P5/10, "Equilibrium theory and optimization for public policy and industry regulation"). Matthias Doepke acknowledges support by the National Science Foundation (grant SES-0217051) and the UCLA Academic Senate. De la Croix: IRES, Place Montesquieu 3, B-1348 Louvain-la-Neuve, Belgium. Doepke: Department of Economics, UCLA, Box 951444, Los Angeles, CA 90095. E-mail addresses: delacroix@ires.ucl.ac.be, doepke@econ.ucla.edu. 


\section{Introduction}

It is one of the main conclusions of family economics that parental choices of fertility and education are interdependent. Parents face a tradeoff between the number of children they have and the amount of resources they spend on the education of each child. Since for educated women the opportunity cost of child-rearing time is high, they will prefer to invest in the education or "quality" of a small number of children. For less educated women, in contrast, the opportunity cost of raising children is low, while providing education is expensive relative to their income. Mothers with little education and low income would therefore prefer to have many children, but invest little in the education of each child. This notion of a quantity-quality tradeoff in the decisions on children, introduced by Becker and Lewis (1973), ${ }^{1}$ is supported by empirical evidence on the cross-sectional distribution of fertility and education. Table 1 shows that fertility falls with the mother's education both in developed countries (first row) and in developing countries (last three rows). The fertility differential between women with high and low education is especially large in developing countries. Similarly, the education level of a child depends positively on the education of the parents (see Fernández and Rogerson 2001).

If fertility and education are joint decisions, government policies regarding education will also have an effect on fertility behavior. In this paper, we analyze the properties of different education systems in a framework that accounts for the joint decision problem of parents regarding fertility and education. Specifically, we compare the implications of a public and a private schooling regime for economic growth and the evolution of the income distribution. Our model allows for inequality across families, and reproduces the salient features of the income-fertility and income-education relationships found in the data. Our main finding is that while private schooling leads to higher growth when there is little inequality in human capital endowments across families, public schooling can dominate when inequality is sufficiently high. This result is driven by the effects of the schooling regime on fertility differentials within the population.

In our model economy, parents decide on their number of children and on the ed-

\footnotetext{
${ }^{1}$ Recent work on the quantity-quality tradeoff includes Becker, Murphy, and Tamura (1990) and Tamura (1994). These papers were the first to demonstrate how different development regimes can arise from endogenous fertility decisions.
} 


\begin{tabular}{ccccc}
\hline & & \multicolumn{3}{c}{ Total Fertility Rate } \\
\cline { 3 - 5 } Survey & \# of Countries & < Elementary & Elementary & Secondary+ \\
\hline WFS, 1975-1979 & 13 EUR/US & 2.40 & 2.17 & 1.79 \\
WFS, 1974-1982 & 30 DC & 6.5 & 5.5 & 4.0 \\
DHS, 1985-1989 & 26 DC & 5.7 & 4.9 & 3.6 \\
DHS, 1990-1994 & 27 DC & 5.29 & 4.72 & 3.29 \\
\hline
\end{tabular}

Source: Kremer and Chen (2000). WFS: World Fertility Survey. DHS: Demographic and Health Survey. "Secondary+" is the average of low secondary, high secondary, and post-secondary, where appropriate.

Table 1: Total Fertility Rates by Education

ucation of each child. Endogenous growth is driven by the accumulation of human capital. With private schooling, the model generates a fertility differential between parents with low and high human capital. Parents with low human capital have many children and provide little education to each child. Since the parents who provide the least education have the highest fertility rates, when inequality is high, average education is low. With public schooling, the fertility differential between rich and poor disappears. If inequality in human capital is high, this leads to higher average education levels in the public schooling regime than in the private regime. Comparing the two regimes, growth will be higher with private education when inequality is low, while the opposite holds when inequality is high.

Another role for public education is related to the dynamics of income distribution. Differential fertility introduces a centrifugal force in the economy: higher reproduction rates by low-skilled people increase the relative number of the poor and can reduce their relative income. Because public education eliminates the fertility differential between skilled and unskilled, it offsets this centrifugal force.

Our results underline the importance of accounting for the joint fertility-education decision when analyzing educational policies. The existing literature on the respective merits of public and private education has mostly relied on models with exogenous fertility. It is instructive to compare our results to Glomm and Ravikumar (1992), who analyze the choice of an education regime in an endogenous growth model with fixed fertility. Glomm and Ravikumar find, as we do, that public schooling can lead 
to higher growth only if initial inequality is high, but they arrive at this conclusion for different reasons. In their model, the friction favoring private schooling is a fiscal externality, which is not present in our model. Public schooling can dominate in terms of growth if the income distribution is sufficiently unequal, and the production function for human capital is sufficiently concave. Concavity also makes public schooling more attractive in our model, but a second key factor in favor of public schooling is the endogenous fertility differential.

Our results are also related to a literature that considers the effect of local financing of public schools, which is the predominant model in the United States. Our analysis implicitly assumes that the public schooling regime is national, i.e., all students in the public regime receive the same amount of education. If public schooling is locally financed, spending per child becomes a function of average income in a given school district. Bénabou (1996a) and Fernández and Rogerson (1998) find that local financing can lead to stratification in income levels across localities, which ultimately results in educational segregation despite a public schooling system. Bénabou (1996b) and Fernández and Rogerson $(1996,1997)$ show how state and local regulations affect education finance and inequality in this environment. Tamura (2001) points out that whether convergence occurs across school districts with different income levels depends on the relative importance of teacher quality versus class size for human capital accumulation. Tamura argues that convergence will occur if teacher quality matters more, and he finds empirical support for the importance of teacher quality in U.S. data. The literature on local school financing generally does not take account of the joint determination of fertility and education decisions. Our analysis could be extended to a model with local school districts, in which case migration and externalities across localities would be key determinants of convergence and growth.

The long-run impact of existing fertility differentials on educational outcomes and the income distribution has been studied by Mare (1997) and Fernández and Rogerson (2001). Mare (1997) finds that fertility differentials per se are too small in the U.S. to have large effects on average education. ${ }^{2}$ Fernández and Rogerson (2001), on the other hand, show that the association of fertility differentials with the degree of marital sorting can lead to sizable long-run effects. While the last two papers take poli-

\footnotetext{
${ }^{2}$ This is consistent with our theory, since the U.S. has a strong public education system, and fertility differentials are therefore expected to be small. Fertility differentials are larger in developing countries, and are correlated with inequality; see Table 1 and Kremer and Chen (2000).
} 
cies as given, Knowles (1999b) demonstrates that accounting for endogenous fertility differentials is important for understanding the long-run consequences of redistributional policies. Specifically, direct income transfers tend to increase fertility differentials, and can thereby have perverse long-run effects on the income distribution. The theoretical framework used here derives from de la Croix and Doepke (2002), who examine the importance of fertility differentials for explaining the empirical relationship between inequality and growth.

The paper is organized as follows. Section 2 presents the model with private and public education and derives optimal fertility and education choices. In Sections 3 and 4 , we compare the dynamic properties of the economy under the two education regimes, and contrast the implications of private and public education for growth and inequality. Section 5 concludes.

\section{The Model}

\subsection{Setup with Private Education}

The model economy is populated by overlapping generations of people who live for two periods, childhood, and adulthood. Time is discrete and goes from 0 to $\infty$. All decisions are made in the adult period of life. People are indexed by $i$ and differ only in their human capital endowment $h_{t}^{i}$. Adults care about consumption $c_{t}^{i}$, their number of children $n_{t}^{i}$, and the human capital of children $h_{t+1}^{i}$. The utility function is given by:

$$
\ln \left(c_{t}^{i}\right)+\gamma \ln \left(n_{t}^{i} h_{t+1}^{i}\right)
$$

The parameter $\gamma>0$ is the altruism factor. Notice that parents care about both child quantity $n_{t}^{i}$ and quality $h_{t+1}^{i}$. As we will see below, the tradeoff between quantity and quality is affected by the human capital endowment of the parent.

Raising one child takes fraction $\phi \in(0,1)$ of an adult's time. An adult has to choose consumption $c_{t}^{i}$, the number of children $n_{t}^{i}$, and education per child $e_{t}$. Education is provided by teachers, and we assume that the average human capital of teachers equals the average human capital in the population $\bar{h}_{t}$. Education $e_{t}^{i}$ is measured in units of time of the average teacher, so that the total education cost for $n_{t}^{i}$ children 
is given by $n_{t}^{i} e_{t}^{i} \bar{h}_{t}$. The budget constraint for an adult with human capital $h_{t}^{i}$ is then given by:

$$
c_{t}^{i}+n_{t}^{i} e_{t}^{i} \bar{h}_{t}=h_{t}^{i}\left(1-\phi n_{t}^{i}\right) .
$$

Here the price of the consumption good and the wage per unit of human capital are normalized to one because production is linear in human capital. The assumption that teachers instead of parents provide education is crucial for generating fertility differentials. It implies that the cost of education per child is independent of the parent's wage. In contrast, since raising each child takes a fixed amount of the parent's time, having many children is more costly for parents who have high wages. Parents with high human capital and high wages therefore substitute child quality for child quantity, and decide to have fewer children with more education. ${ }^{3}$

The human capital of the children $h_{t+1}^{i}$ depends on human capital of the parents $h_{t}^{i}$, average or teacher's human capital $\bar{h}_{t}$, and education $e_{t}^{i}$ :

$$
h_{t+1}^{i}=\mu\left(\theta+e_{t}^{i}\right)^{\eta}\left(h_{t}^{i}\right)^{\tau}\left(\bar{h}_{t}\right)^{1-\tau} .
$$

The parameters satisfy $\mu, \theta>0$ and $\eta, \tau \in(0,1)$. The presence of $\theta$ guarantees that human capital remains positive even if parents do not invest in education. This accumulation technology assumes diminishing returns to parental human capital, but constant returns to scale in parental human capital and teacher human capital. This assumption is common in the literature (see, e.g., Tamura 1991; de la Croix and Michel 2002) where the spillover effect of average human capital is found to be crucial for human capital convergence.

We assume that the population is divided into two groups $A$ and $B$ with human capital $h_{t}^{A}$ and $h_{t}^{B}$, where $A$ is the group with less human capital: $h_{t}^{A}<h_{t}^{B}$. The absolute sizes of the groups are given by $P_{t}^{A}$ and $P_{t}^{B}$. The law of motion for the group sizes is:

$$
P_{t+1}^{i}=P_{t}^{i} n_{t}^{i}
$$

Their initial relative size is:

$$
\xi_{t}=\frac{P_{t}^{A}}{P_{t}^{B}} .
$$

\footnotetext{
${ }^{3}$ To generate fertility differentials we only need to assume that the education cost is independent of the parent's wage. The more specific assumption that the teachers have the same average human capital as the general population is made to allow for balanced growth.
} 
In this formulation we abstract from inter-group mobility and in particular from mobility through mating. The extent to which mating can reduce the "inheritability" of skills is limited by the fact that mating is assortative on average. ${ }^{4}$ Average human capital is given by:

$$
\bar{h}_{t}=\frac{P_{t}^{A} h_{t}^{A}+P_{t}^{B} h_{t}^{B}}{P_{t}^{A}+P_{t}^{B}} .
$$

The aggregate production function for the consumption good is linear in the aggregate supply of effective labor:

$$
Y_{t}=L_{t}
$$

where $L_{t}$ is given by:

$$
L_{t}=P_{t}^{A}\left(h_{t}^{A}\left(1-\phi n_{t}^{A}\right)-e_{t}^{A} n_{t}^{A} \bar{h}_{t}\right)+P_{t}^{B}\left(h_{t}^{B}\left(1-\phi n_{t}^{B}\right)-e_{t}^{B} n_{t}^{B} \bar{h}_{t}\right) .
$$

Notice that the education time for all children is subtracted from total labor supply, since time devoted to teaching is not available for goods production. Since the total efficiency units of labor needed for education are fixed, it does not matter who provides the education in equilibrium. For simplicity, we assume without loss of generality that there is an identical share of teachers in both groups. We assume that production is carried out by a competitive firm, which implies that the wage per unit of human capital is one. Instead of writing out this condition explicitly, we already incorporated it in the budget constraint.

Definition 1 (Private-Education Equilibrium) Given initial human capital endowments $\left(h_{0}^{A}, h_{0}^{B}\right)$ and group sizes $\left(P_{0}^{A}, P_{0}^{B}\right)$, an equilibrium with private education consists of sequences of aggregate quantities $\left\{\xi_{t}, \bar{h}_{t}, L_{t}\right\}$, group sizes $\left\{P_{t+1}^{i}\right\}_{i=A, B}$, and decision rules $\left\{c_{t}^{i}, n_{t}^{i}, e_{t}^{i}, h_{t+1}^{i}\right\}_{i=A, B}$ such that:

1. the households' decision rules $c_{t}^{i}, n_{t}^{i}, e_{t}^{i}, h_{t+1}^{i}$ maximize utility subject to the constraints (1) and (2);

2. the group populations evolve according to (3);

\footnotetext{
${ }^{4}$ See Kremer (1997) and Fernández and Rogerson (2001) on the effects of sorting and assortative mating on long-run inequality; Gokhale, Kotlikoff, Sefton, and Weale (2001) on the interaction between mating processes, the inheritability of skills, and the inter-generational transmission of inequality; and Preston and Campbell (1993) on differential fertility and the distribution of IQ.
} 
3. aggregate variables $\xi_{t}, \bar{h}_{t}$, and $L_{t}$ are given by (4), (5), and (6).

\subsection{Fertility and Education Choices Under Private Education}

We denote the relative human capital of a household as:

$$
x_{t}^{i} \equiv \frac{h_{t}^{i}}{\bar{h}_{t}}
$$

The solution to the household decision problem can either be interior, or at a corner where the household chooses zero education. For a household that has enough human capital such that the condition $x_{t}^{i}>\frac{\theta}{\phi \eta}$ holds, there is an interior solution for the optimal education level, and the first-order conditions imply:

$$
\begin{aligned}
& e_{t}^{i}=\frac{\eta \phi x_{t}^{i}-\theta}{1-\eta}, \quad \text { and: } \\
& n_{t}^{i}=\frac{(1-\eta) \gamma x_{t}^{i}}{\left(\phi x_{t}^{i}-\theta\right)(1+\gamma)} .
\end{aligned}
$$

The second-order conditions for a maximum are satisfied. Note that education increases in human capital $x^{i}$, while fertility decreases in $x^{i}$. This reflects the fact that skilled people invest relatively more in the quality of their children than in their quantity (see Table 1 and the discussion in the introduction). The lowest possible fertility rate is given by:

$$
\lim _{x_{t}^{i} \rightarrow \infty} n_{t}^{i}=\frac{\gamma(1-\eta)}{\phi(1+\gamma)}
$$

For a household endowed with a human capital such that $x_{t}^{i} \leq \frac{\theta}{\phi \eta}$ holds, the optimal choice for education $e_{t}^{i}$ is zero. The first-order conditions imply:

$$
\begin{aligned}
e_{t}^{i} & =0, \quad \text { and: } \\
n_{t}^{i} & =\frac{\gamma}{\phi(1+\gamma)} .
\end{aligned}
$$

Once the choice for education is zero, fertility in equation (10) no longer increases as the human capital endowment falls. To ensure that at least households of type $B$ invest in education, i.e. $e^{B}>0 \forall x^{B}>1$, we impose an upper bound on $\theta$ in the 
following assumption:

\section{Assumption 1}

The parameters satisfy the following condition:

$$
\eta \phi>\theta .
$$

When Assumption 1 does not hold, the amount of human capital one receives even without investing in education is so high that a parent with average human capital $(x=1)$ would chose zero education.

Fertility as a function of relative human capital is plotted in Figure 1. The horizontal part of the relationship corresponds to the range of human capital which leads to a choice of zero for education $e_{t}$. Fertility depends negatively on human capital, and moves within a finite interval. The upper bound on the fertility differential is given by:

$$
\frac{\lim _{x_{t} \rightarrow 0} n_{t}}{\lim _{x_{t} \rightarrow \infty} n_{t}}=\frac{1}{1-\eta} .
$$

The fertility differential between people with low and high human capital tends to lower the growth rate of the economy, since the parents who do not invest in education have the highest number children. As we will see later, this differential-fertility effect has implications for the advantages of public and private education.

\subsection{The Setup with Public Education}

In the public education regime, parents do not choose an individual education level for their children. Instead, the government levies a proportional income tax $v_{t}$ on all adults, and uses the proceeds to finance a common education level $\bar{e}_{t}$ for all children. Budget balance is observed in every period. The budget constraint for an adult with human capital $h_{t}^{i}$ now becomes:

$$
c_{t}^{i}=\left(1-v_{t}\right) h_{t}^{i}\left(1-\phi n_{t}^{i}\right) .
$$




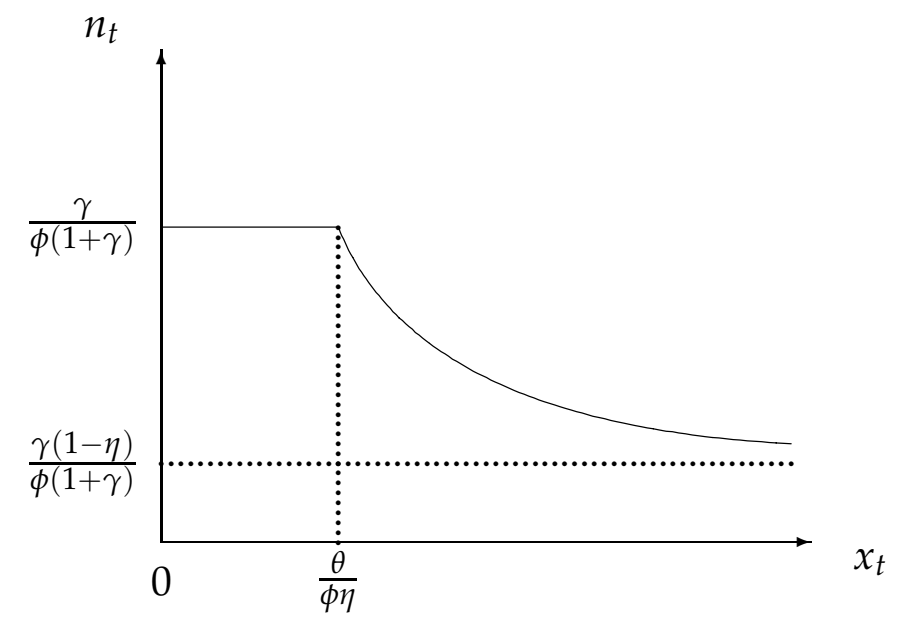

Figure 1: Fertility as a Function of Human Capital

Notice that parents are not allowed to provide private education in addition to the common level of public education. ${ }^{5}$ The human capital of the children $h_{t+1}^{i}$ is now given by:

$$
h_{t+1}^{i}=\mu\left(\theta+\bar{e}_{t}\right)^{\eta}\left(h_{t}^{i}\right)^{\tau}\left(\bar{h}_{t}\right)^{1-\tau} .
$$

Since the government has to observe budget balance, total expenditure on education has to equal total tax receipts at time $t$. The government's budget constraint is given by:

$$
\bar{e}_{t} \bar{h}_{t}\left(P_{t}^{A} n_{t}^{A}+P_{t}^{B} n_{t}^{B}\right)=v_{t}\left(P_{t}^{A} h_{t}^{A}\left(1-\phi n_{t}^{A}\right)+P_{t}^{B} h_{t}^{B}\left(1-\phi n_{t}^{B}\right)\right) .
$$

We assume that $v_{t}$ and therefore $\bar{e}_{t}$ are determined in each period by a vote of the adult population. Since we assume logarithmic utility, it will turn out that all adults prefer the same tax rate. Therefore no conflict of interest arises, and the tax is independent of the distribution of human capital.

Definition 2 (Public-Education Equilibrium) Given initial human capital endowments $\left(h_{0}^{A}, h_{0}^{B}\right)$ and group sizes $\left(P_{0}^{A}, P_{0}^{B}\right)$, an equilibrium with public education consists of sequences of aggregate quantities $\left\{\xi_{t}, \bar{h}_{t}, L_{t}\right\}$, group sizes $\left\{P_{t+1}^{i}\right\}_{i=A, B}$, private decision rules

\footnotetext{
${ }^{5}$ We concentrate on the polar case where all education is provided by the government. Results for mixed regimes where parents can top off the public education would lie in between the polar cases considered here. In particular, the threshold for inequality above which a mixed regime leads to higher growth than a pure private regime would be lower than the threshold for the pure public regime.
} 
$\left\{c_{t}^{i}, n_{t}^{i}, h_{t+1}^{i}\right\}_{i=A, B}$, and policy variables $\left\{v_{t}, \bar{e}_{t}\right\}$, such that:

1. the households' decision rules $c_{t}^{i}, n_{t}^{i}, h_{t+1}^{i}$ maximize utility subject to the constraints (11) and (12);

2. the government's budget constraint (13) is satisfied;

3. given decision rules, the policy variables maximize the utility of adult households;

4. the group populations evolve according to (3);

5. aggregate variables $\xi_{t}, \bar{h}_{t}$, and $L_{t}$ are given by (4), (5), and (6).

\subsection{Fertility and Policy Choices Under Public Education}

Once the education level is fixed by public policy, parents no longer face a qualityquantity tradeoff. Therefore the optimal fertility choice is independent of parental human capital. The first-order condition for $n_{t}$ implies that everyone chooses the same number of children:

$$
n_{t}=\frac{\gamma}{\phi(1+\gamma)}
$$

Since fertility is constant, the government budget constraint (13) simplifies to:

$$
\bar{e}_{t} \frac{\gamma}{\phi(1+\gamma)}=v_{t}\left(1-\frac{\gamma}{1+\gamma}\right)
$$

which can be solved to give:

$$
\bar{e}_{t}=\frac{\phi v_{t}}{\gamma}
$$

Using (14) and (15), the indirect utility of a household with human capital $h_{t}$ is given by:

$$
\ln \left(\left(1-v_{t}\right) h_{t}\left(1-\frac{\gamma}{1+\gamma}\right)\right)+\gamma \ln \left(\frac{\gamma}{\phi(1+\gamma)} \mu\left(\theta+\phi v_{t} / \gamma\right)^{\eta}\left(h_{t}\right)^{\tau}\left(\bar{h}_{t}\right)^{1-\tau}\right) .
$$

The adults choose the tax $v_{t}$ to maximize utility. The first-order condition for a maximum leads to:

$$
v_{t}=\frac{\gamma(\phi \eta-\theta)}{\phi(1+\gamma \eta)}
$$


and the resulting choice for public education is:

$$
\bar{e}_{t}=\frac{\eta \phi-\theta}{1+\gamma \eta} .
$$

The second-order condition for a maximum is satisfied. Assumption 1 guarantees a positive level of public education.

\section{Comparing Private and Public Education}

\subsection{Long-Run Dynamics}

To study the dynamic behavior of the economy, it is useful to introduce the growth rate $g_{t}$ of average human capital:

$$
g_{t}=\frac{\bar{h}_{t+1}}{\bar{h}_{t}} .
$$

Along the balanced growth path, $g_{t}$ is also the growth rate of GDP per capita.

We first consider the private education regime. There cannot be a balanced growth path with group A in the corner regime (no education, high fertility), because it would imply that the relative size of this group would go to 1 . Since we are mainly interested in the dynamics around the balanced growth path, we therefore consider cases where the maximization program of all individuals yields interior solutions. Replacing the optimal education choice (7) into the accumulation law of human capital (2) leads to:

$$
x_{t+1}^{i}=\frac{1}{g_{t}} \mu\left(\frac{\eta}{1-\eta}\right)^{\eta}\left(\phi x_{t}^{i}-\theta\right)^{\eta}\left(x_{t}^{i}\right)^{\tau} .
$$

Using the definitions of relative human capital $x_{t}^{i}=h_{t}^{i} / \bar{h}_{t}$ and the population ratio $\xi_{t}=P_{t}^{B} / P_{t}^{A}$, (5) can be expressed as:

$$
1=x_{t+1}^{A} \frac{\xi_{t+1}}{1+\xi_{t+1}}+x_{t+1}^{B} \frac{1}{1+\xi_{t+1}} .
$$

Replacing $x_{t+1}^{A}$ and $x_{t+1}^{B}$ using equation (17), we obtain an expression for the growth 
rate of average human capital:

$$
g_{t}=\frac{\mu}{1+\xi_{t+1}}\left(\frac{\eta}{1-\eta}\right)^{\eta}\left(\xi_{t+1}\left(\phi x_{t}^{A}-\theta\right)^{\eta}\left(x_{t}^{A}\right)^{\tau}+\left(\phi x_{t}^{B}-\theta\right)^{\eta}\left(x_{t}^{B}\right)^{\tau}\right) .
$$

The law of motion for the population ratio $\xi_{t}$ is obtained by replacing the optimal fertility choice (8) into the law of motion for population (3):

$$
\xi_{t+1}=\frac{x_{t}^{A}\left(\phi x_{t}^{B}-\theta\right)}{x_{t}^{B}\left(\phi x_{t}^{A}-\theta\right)} \xi_{t}
$$

Finally, from the definition of average human capital (5) we have:

$$
x_{t}^{B}=1+\xi_{t}\left(1-x_{t}^{A}\right) .
$$

The set of equations (17) to (20) can be restated as a dynamic system of order two in the variables $\left(x_{t}^{A}, \xi_{t}\right)$. An analysis of this system leads to the following proposition (proven in the appendix):

Proposition 1 Under Assumption 1, there is a balanced growth path of the economy with private education characterized by $x_{t}^{A}=x_{t}^{B}=1$, i.e., inequality has vanished. The growth rate of output and human capital is:

$$
g^{\star}=\mu\left(\frac{\eta(\phi-\theta)}{1-\eta}\right)^{\eta}>0
$$

This balanced growth path is locally stable if:

$$
\tau<1-\frac{\eta \phi}{\phi-\theta}
$$

Along this balanced growth path, there is no longer any inequality among households. This is the case because we have assumed that the only difference across households lies in their initial level of human capital. If we had introduced ability shocks on top of an unequal initial distribution of human capital, inequality would persist along the balanced growth path. However, this inequality would simply reflect the randomness of abilities, and would not change our main conclusions. 
The stability condition imposes an upper limit on the parameter $\tau$. If $\tau$ exceeds this limit, the aggregate externality deriving from $\bar{h}_{t}$ in equation (2) is not strong enough to offset the effect of parental human capital $h_{t}^{i}$, and inequality will persist or increase over time.

We now turn to the case of public education. Since parents with high and low human capital have the same number of children, the relative size of the groups is constant over time:

$$
\xi_{t+1}=\xi_{t}=\xi_{0}
$$

To analyze the dynamics of the economy, we replace the public education level (16) into the accumulation law of human capital (2). For type-i households, this leads to:

$$
x_{t+1}^{i}=\frac{1}{g_{t}} \mu\left(\frac{\eta(\theta \gamma+\phi)}{1+\gamma \eta}\right)^{\eta}\left(x_{t}^{i}\right)^{\tau} .
$$

Combining this with (20) gives:

$$
1+\xi_{0}\left(1-x_{t+1}^{A}\right)=\frac{1}{g_{t}} \mu\left(\frac{\eta(\theta \gamma+\phi)}{1+\gamma \eta}\right)^{\eta}\left(1+\xi_{0}\left(1-x_{t}^{A}\right)\right)^{\tau} .
$$

Replacing $g_{t}$ by its value from (21), we obtain:

$$
x_{t+1}^{A}=\frac{1+\xi_{0}}{\xi_{0}+\left(\frac{1+\xi_{0}}{x_{t}^{A}}-\xi\right)^{\tau}} .
$$

The dynamics described by equation (22) are monotone, and $x_{t}^{A}$ converges to 1 for any $\tau<1$. Along the balanced growth path, the growth rate can be computed by setting $x^{A}=1$ in equation (21). The analysis leads to the following proposition (proven in the appendix):

Proposition 2 Under Assumption 1, there is a balanced growth path of the economy with public education characterized by $x_{t}^{A}=x_{t}^{B}=1$, i.e., inequality has vanished. The growth rate of output and human capital is:

$$
g^{\circ}=\mu\left(\frac{\eta(\theta \gamma+\phi)}{1+\gamma \eta}\right)^{\eta}>0 .
$$

This balanced growth path is globally stable. 
In summary, both under private and public education there exists a balanced growth path in which all inequality has vanished. The stability properties of the two education regimes, however, are different. Under public education, all children receive the same education. Since we assume that the children's human capital increases less than proportionally with the parent's human capital $(\tau<1)$, this implies that inequality decreases over time. From any initial conditions, the economy with public education converges to a balanced growth path in which inequality had disappeared.

In the private regime, education choices differ across the two groups. Children whose parents have an above-average human capital endowment receive above-average education. If the effect of parental human capital on their children's human capital is sufficiently large, the combined effect of parental endowments and education can lead to rising inequality. In that case, the economy does not converge to the balanced growth path, and the income difference between the two groups can grow without bounds.

Note that, in our framework, the only public education regime is a national education regime. It approximates countries where the central government organizes education, like the majority of developing countries, and much of Europe. If one considers the possibility that school districts may not be national in scale, convergence can still predominate, either because the difference in education of teachers across school districts is smaller than the differences in education of parents (Tamura 2001), or because there are knowledge spillovers across districts (de la Croix and Monfort 2000), or because stratification is slowed down by higher housing rents in rich districts (Bénabou 1996c). If convergence still prevails, it will be at a slower pace than with a national education system, because resources put into the regional public education system will rely more heavily on the district income level, and redistribution across regions through taxes will be lower.

\subsection{Implications for Growth}

On a balanced growth path, both regimes display constant fertility and education, and the choice for education is lower in the public education regime. From (7), in the 
private regime the education choice on the balanced growth path is given by:

$$
e=\frac{\eta \phi-\theta}{1-\eta}
$$

while in the public regime education is (16):

$$
\bar{e}=\frac{\eta \phi-\theta}{1+\gamma \eta},
$$

which is clearly lower. The choice of fertility, on the other hand, is higher with public education. In the private regime, fertility is given by (8):

$$
n=\frac{1-\eta}{\gamma}(\phi-\theta)(1+\gamma),
$$

while in the public regime fertility is (14):

$$
n=\frac{\gamma}{\phi(1+\gamma)} .
$$

Given that Assumption 1 holds, (24) always exceeds (23). The growth rate along the balanced growth path depends directly on education. Therefore, once the balanced growth path is reached, growth is always higher in the private regime. The following proposition summarizes these findings.

Proposition 3 Under Assumption 1, along a balanced growth path, education and growth are lower under public education than under private education, while fertility is higher.

The reason for the growth rate differential is that in the public regime, parents do not internalize the negative effect of having many children on the education resources per child. Therefore they choose a relatively higher number of children, and education spending per child is smaller than in the private regime.

Even if the economy is not on the balanced growth path, fertility and education are fixed in the public education regime. In the private education regime, however, both choice variables depend on the parent's human capital. Adults with low human capital invest less in education and have a higher number of children. Both effects tend 
to lower the growth rate of human capital. This opens the possibility for the public regime to yield higher growth.

Using the production function for human capital (2) and equation (3), the growth rate $g_{t}$ of average human capital is given by:

$$
\begin{aligned}
g_{t}=\frac{\bar{h}_{t+1}}{\bar{h}_{t}} & =\frac{P_{t}^{A} n_{t}^{A} h_{t+1}^{A}+P_{t}^{B} n_{t}^{B} h_{t+1}^{B}}{\bar{h}_{t}\left(P_{t}^{A} n_{t}^{A}+P_{t}^{B} n_{t}^{B}\right)} \\
& =\mu \frac{\xi_{t} n_{t}^{A}\left(\theta+e_{t}^{A}\right)^{\eta}\left(x_{t}^{A}\right)^{\tau}+n_{t}^{B}\left(\theta+e_{t}^{B}\right)^{\eta}\left(x_{t}^{B}\right)^{\tau}}{\xi_{t} n_{t}^{A}+n_{t}^{B}} .
\end{aligned}
$$

This expression holds for both private and public education, and shows that the growth rate depends on the education choices of groups $A$ and $B$, and the relative weight of their children in tomorrow's population.

Allowing for endogenous fertility has two distinct effects on the growth rate of human capital. First, the additional margin of family size increases the difference in the education choice $e_{t}^{i}$ between the two groups, since poor households substitute out of education and into the quantity of children. If we imposed a constant number of children on all households, the group with more human capital would still choose more education, but for given human capital levels $x_{t}^{A}$ and $x_{t}^{B}$ the difference in education $e_{t}^{B}-e_{t}^{A}$ would be smaller than with endogenous fertility. Second, under private education endogenous fertility introduces a fertility differential between poor and rich parents. Therefore in (25) additional weight is placed on the group with higher fertility. Since under private education fertility is higher for parents with little human capital, the fertility differential hampers growth of human capital.

Recall that in the private regime the education choice is given by equations (7) and (9), i.e.:

$$
e_{t}^{i}=\max \left\{\frac{\eta \phi x_{t}^{i}-\theta}{1-\eta}, 0\right\},
$$

while in the public regime education is given by (16):

$$
e_{t}^{i}=\frac{\eta \phi-\theta}{1+\gamma \eta}
$$


Since group $B$ is defined as the one with higher human capital, we have $x_{t}^{B} \geq 1$, and therefore their education is always higher in the private than in the public regime. For group $A$, the private regime yields higher education only if $x_{t}^{A}$ is close to one. Comparing the two expressions, we find that education will be higher in the private regime if $x_{t}^{A}$ is large enough to satisfy the following condition:

$$
x_{t}^{A} \geq \frac{\phi(1-\eta)+\theta(1+\gamma)}{\phi(1+\gamma \eta)} .
$$

If condition (26) is met, the private regime must lead to higher growth than the public regime, since education is higher for both types of parents. If $x_{t}^{A}$ is sufficiently low such that (26) is violated, which regime results in higher growth depends on the relative population weight of the two groups.

Proposition 4 Assume that Assumption 1 holds, and that the parameters satisfy $\eta+\tau<1$. Then for a given $x_{t}^{A}$ sufficiently low to violate (26), there exists a threshold for $\xi_{t}$ above which the public education regime yields higher growth than the private education regime.

Proof: Fix an $x_{t}^{A}$ violating (26). Assume that the relative size $\xi_{t}$ of group $A$ goes to infinity while holding $x_{t}^{A}$ constant, and notice that $x_{t}^{B}$ depends on $x_{t}^{A}$ and $\xi_{t}$ and is given by (20):

$$
x_{t}^{B}=1+\xi_{t}\left(1-x_{t}^{A}\right)
$$

while $e_{t}^{B}$ is given by (7):

$$
e_{t}^{B}=\frac{\eta \phi x_{t}^{B}-\theta}{1-\eta} .
$$

Thus both $x_{t}^{B}$ and $e_{t}^{B}$ are asymptotically linear in $\xi_{t}$. The growth rate $g_{t}$ is given by (25):

$$
g_{t}=\mu\left(\frac{\xi_{t} n_{t}^{A}\left(\theta+e_{t}^{A}\right)^{\eta}\left(x_{t}^{A}\right)^{\tau}}{\xi_{t} n_{t}^{A}+n_{t}^{B}}+\frac{n_{t}^{B}\left(\theta+e_{t}^{B}\right)^{\eta}\left(x_{t}^{B}\right)^{\tau}}{\xi_{t} n_{t}^{A}+n_{t}^{B}}\right) .
$$

Since $n_{t}^{i}$ is bounded and we assume $\eta+\tau<1$, the second term inside the parentheses converges to zero as $\xi_{t}$ goes to infinity. The limit is therefore given by:

$$
\lim _{\xi_{t} \rightarrow \infty} g_{t}=\mu\left(\theta+e_{t}^{A}\right)^{\eta}\left(x_{t}^{A}\right)^{\tau} .
$$


Thus in the limit only the education choices of group $A$ will matter for growth. Since we assume that (26) is violated, group $A$ chooses higher education under public than under private education. Therefore, there is some $\xi_{t}$ sufficiently high such that the growth rate of average human capital is higher in the public regime than in the private regime.

In summary, when the economy is not on the balanced growth path, growth can be higher either in the public or in the private regime. If there is little inequality ( $x_{t}^{A}$ is close to one) or if group $B$ makes up a large fraction of the population, the private regime will yield higher growth. If $x_{t}^{A}$ is sufficiently low to violate (26), and if the relative size $\xi_{t}$ of group $A$ is sufficiently large, the public regime will lead to higher growth. Thus, the question which regime leads to higher growth hinges on the initial distribution of income and population. Moreover, as the economy evolves over time, the relative income and size of the two groups changes, which can revert the advantages of the two regimes. This possibility is explored in more detail in the next section.

\section{Growth and Inequality over Time}

In this section we analyze the effects of private and public education on the evolution of growth and inequality. In particular, we want to demonstrate that the ranking of the two regimes in terms of economic growth can switch as the income distribution changes over time. For this purpose we compute outcome paths for a parameterized version of our economy under private and public education. The key parameter governing dynamics in the model is the elasticity $\tau$ of children's human capital with respect to their parents' human capital, and we compute outcomes for a range of values for $\tau$. The remaining parameters have been calibrated to match the balanced growth path of the private-education model to U.S. data.

\subsection{Calibration}

The overall productivity $\mu$ does not affect decisions and growth rate differentials and can therefore be chosen arbitrarily; we set it such that the balanced growth rate is $2 \%$ 
per year. The altruism parameter $\gamma$ is chosen such that the growth rate of population in the balanced growth path is zero. This leads to $\gamma=0.169$. The elasticity $\eta$ of human capital with respect to education governs the maximum fertility differential. To prevent inflating the role of fertility differentials, it is important not to choose $\eta$ too high. A conservative estimate is $\eta=0.6$, which leads to a maximum fertility ratio of 2.5 (i.e., if minimum fertility is two children per woman, the maximum is five). This is well below the maximum differentials observed within countries. The time-cost parameter $\phi$ for having a child determines the overall opportunity cost of children. Evidence in Haveman and Wolfe (1995) and Knowles (1999a) suggests that the opportunity cost of a child is equivalent to about $15 \%$ of the parents' time endowment. This cost only accrues as long as the child is living with the parents. If we assume that children live with parents for 15 years and that the adult period lasts 30 years, the overall time cost should be $50 \%$ of the time cost per year with the child present. Accordingly, we choose $\phi=0.075$. The parameter $\theta$ in the production function for human capital affects the education choice of parents, and therefore determines the aggregate expenditures on education. We choose $\theta$ such that in the balanced growth path of the private education regime, total education expenditure as a fraction of GDP matches the corresponding value in U.S. data, which is about 7.5\% (see U.S. Department of Education 1998). The implied choice is $\theta=0.017$. The remaining parameter $\tau$ determines the weight of parental human capital in the production of children's human capital. In other words, $\tau$ captures the intergenerational transmission of ability, as well as human capital formation within the family that does not work through formal schooling. Empirical studies find such effects to be relatively small. Rosenzweig and Wolpin (1994) estimate that an additional year of the mother's education at the high school level (roughly a 10 percent increase in education) raises a child's test scores by 2.4 percent. Arleen Leibowitz (1974) finds that even after controlling for schooling and education of the parents, parental income has a significant effect on a child's earnings. A 10 percent increase in parental income increases a child's future earnings by up to 0.85 percent. Since $\tau$ has a large effect on the dynamic properties of the model, we leave it unspecified for now and compute outcomes for a range of different choices for $\tau$. The threshold for $\tau$ below which the private education balanced growth path is stable is $1-\frac{\eta \phi}{\phi-\theta}=0.224$. The empirical studies suggest that the stable region of the parameter space is the empirically relevant case. Given our parameter choices, the human capital threshold below which people do not educate 


$$
\tau=0
$$

$\xi_{0}$

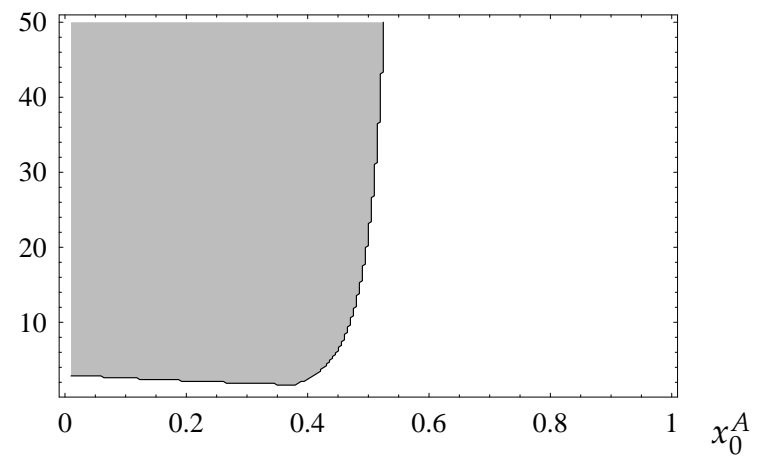

$$
\tau=0.2
$$

$\xi_{0}$

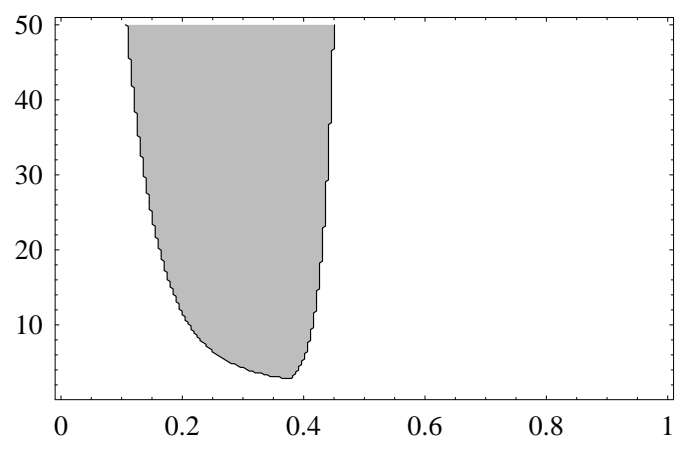

$\tau=0.1$

$\xi_{0}$

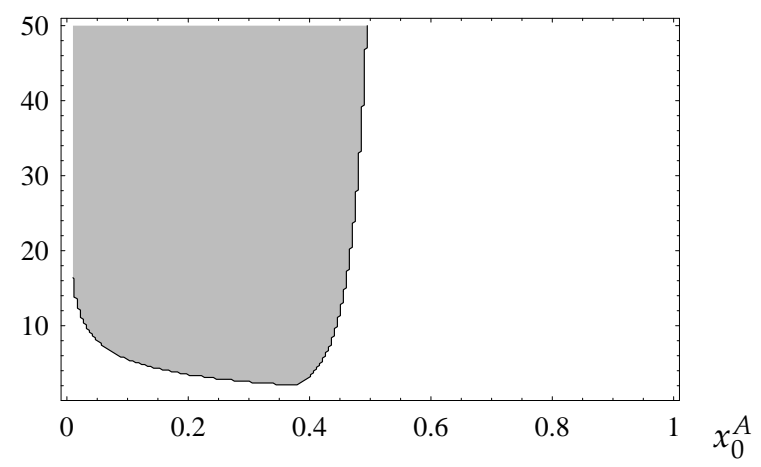

$\tau=0.3$

$\xi_{0}$

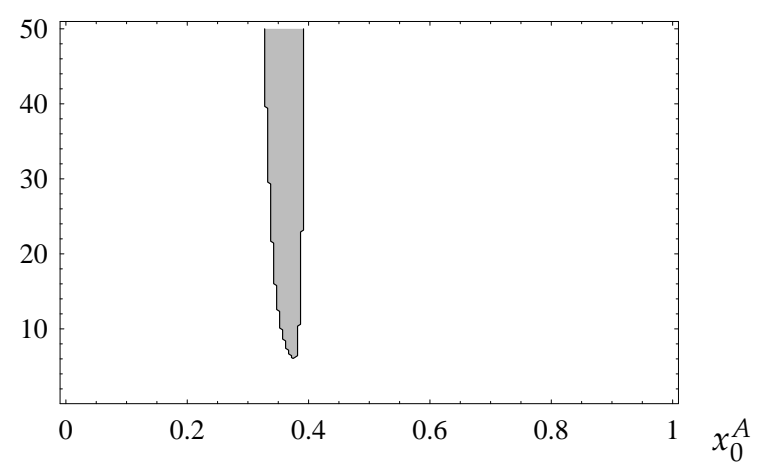

Figure 2: Initial Conditions for which Growth is Higher with Public Education their children is $\theta /(\eta \phi)=0.38$.

\subsection{Initial Conditions and Growth}

We found in the last section that private education will always lead to higher growth if inequality is low, but public education can dominate if inequality is high. Figure 2 shows the range of initial conditions $\xi_{0}$ and $x_{0}^{A}$ for which public education leads to higher growth in the parameterized economy, for four different values of $\tau$. In all cases, private education dominates for $x_{0}^{A}$ that exceed a value of about 0.6. Below this value, there is a zone in which public schooling dominates, and the size of this zone 
is decreasing in $\tau$. The range of $x_{0}^{A}$ for which public education yields more growth increases in $\xi_{0}$, i.e., public education is more likely to be advantageous when group $A$ is relatively large.

Interestingly, when the relative human capital $x_{0}^{A}$ becomes very low, private schooling dominates once again. The reason is that there is a lower limit for the education of group $A$ (at zero), and an upper limit for fertility. Once $x_{0}^{A}$ is low enough to reach the corner solution for education and fertility, the only effect of decreasing $x_{0}^{A}$ further is to increase $x_{0}^{B}$ and therefore the education of group $B$, which raises growth. This same effect does not arise in the public education regime, since fertility and education are independent of $x_{0}^{A}$ and $x_{0}^{B}$.

The influence of $\tau$ on the regions is related to the allocation of total education spending on groups $A$ and $B$. Notice that fertility and education decisions are independent of $\tau$. Therefore the only effect of changing $\tau$ on growth is the direct one-through the weight of parental human capital in the production function for $h_{t+1}^{i}$. When $\tau$ is zero, parental human capital has no direct effect on the children's human capital. For a given amount of total spending, growth is maximized if equal amounts are spent on children of type- $A$ and type- $B$ parents. Since spending is equalized under public schooling, the region of higher growth under public schooling is large when $\tau$ is small. When $\tau$ is large, the return on education is higher for type- $B$ children, since they benefit more from parental human capital. Education for type- $B$ children is higher under private schooling; thus private education yields higher growth.

\subsection{Human Capital Accumulation and Inequality Dynamics}

Figures 3 and 4 show how human capital and inequality evolve over time under public and private schooling. ${ }^{6}$ The only difference between the two figures concerns the value of the parameter $\tau$. The balanced growth path with private education is stable in Figure 3 with $\tau=0.22$, while it is unstable in Figure 4 with $\tau=0.5$. In both case, the other parameters are set as described in Section 4.1, and the initial condition is $\xi_{0}=90$ and $x_{0}^{A}=0.38$. At this initial condition, group $A$ chooses zero education in the private regime.

\footnotetext{
${ }^{6}$ In our economy human capital is a better measure of wealth than GDP per capita, as the number of children enters utility, but time spent raising children does not enter GDP.
} 

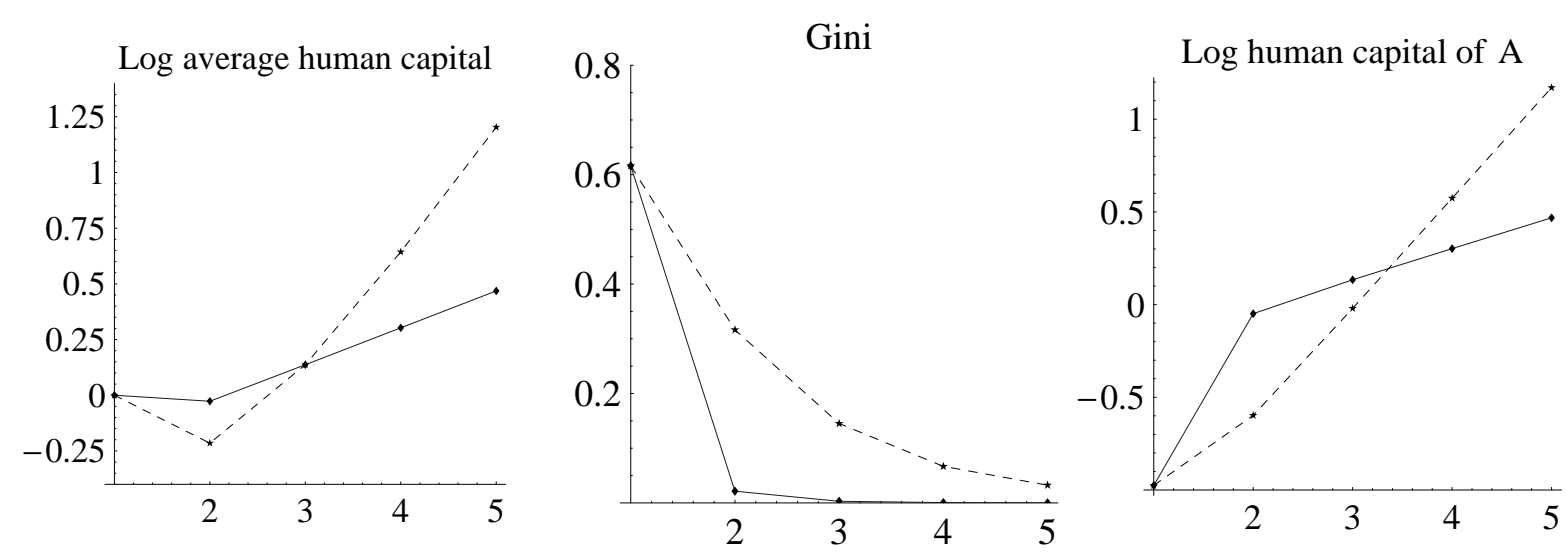

Figure 3: Dynamics with Public (Solid Line) and Private Education (Dashes): $\tau=0.22$

We first consider Figure $3(\tau=0.22)$, so that the dynamics are stable. Average human capital, the Gini coefficient for the distribution of human capital, and human capital of the poorest group are plotted for the first five periods. ${ }^{7}$ In the initial period, growth of average human capital is higher with public schooling, as it has to be given our choice of initial conditions. Inequality falls under both public and private education. In the private regime, the children of group- $B$ parents receive more education, but since $\tau$ is low, parental human capital has little effect and inequality still declines. In the second period, the growth advantage shifts to the private regime, since $x^{A}$ has increased, and the education and fertility differential is reduced. From the second period on, as $x^{A}$ approaches one, average human capital per capita keeps increasing in both regimes, but growth is higher with private education. Inequality is further reduced in each case, with the faster reduction occurring under public education.

If the objective were to maximize growth, the optimal policy would be to start out with public education, and switch to private education later on. An unambiguous welfare ranking of the policies is not possible, since at least initially the two groups have opposing interests, and there is no obvious method of accounting for population changes when evaluating welfare. However, given that inequality is reduced faster under public education, it is apparent that if policies were chosen according to a welfare function which places most weight on group $A$, public education could be maintained longer than in the growth-maximizing policy. This is reflected in the third panel of the Figure where the human capital of the poorest group benefits from

\footnotetext{
${ }^{7}$ The Gini index can be computed as $\xi_{t}\left(1-x_{t}^{A}\right) /\left(1+\xi_{t}\right)$.
} 

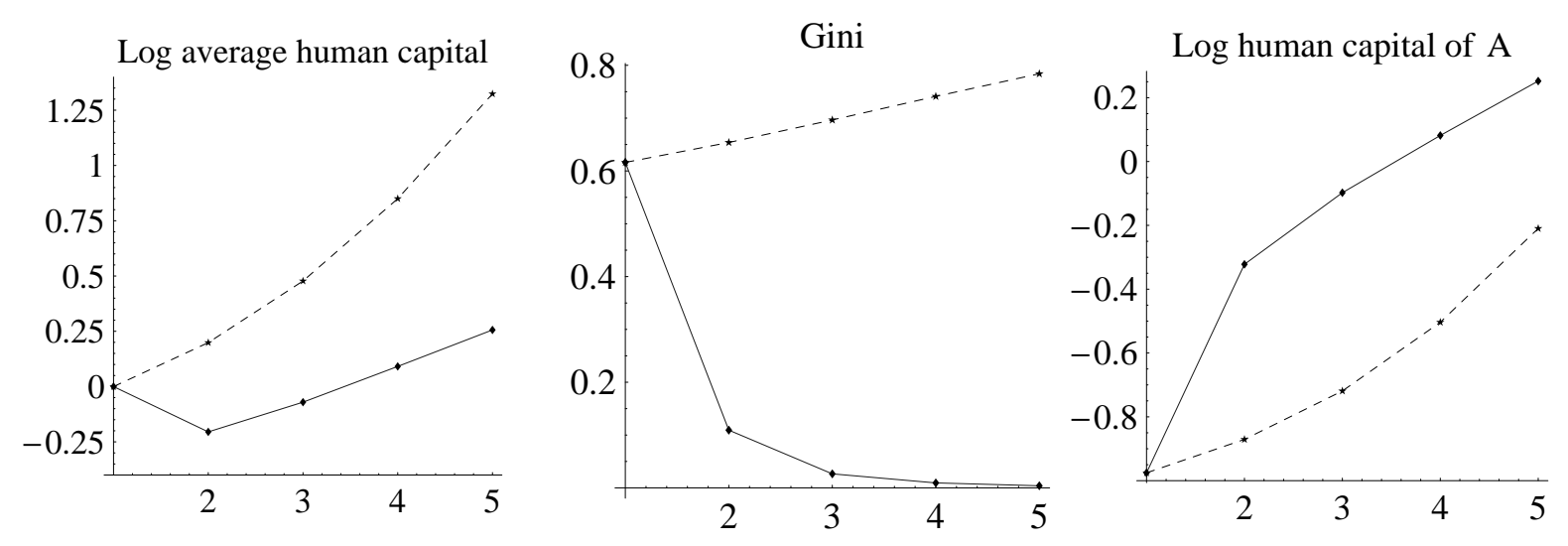

Figure 4: Dynamics with Public (Solid Line) and Private Education (Dashes): $\tau=0.5$

public education until $t=3$, i.e. one more period than average human capital.

The graphs in Figure 4 show average human capital, inequality, and human capital of group $A$ for $\tau=0.5$, a value well above the stability limit. For this value of $\tau$, private schooling always gives higher growth than public schooling. Consequently, average human capital is higher under private schooling from the first period on. However, the higher growth rate comes at the price of increased inequality. Under public schooling, inequality decreases over time, and the economy converges to the balanced growth path without inequality. Under private schooling, $x_{t}^{A}$ converges to zero and the Gini coefficient converges to one. At the same time, fertility is permanently higher for group $A$, implying that in the limit group $A$ makes up 100 percent of the population, while accounting for zero percent of the income. Thus even though private schooling maximizes growth unambiguously, the tradeoff between growth and inequality is even more stark than before. Given that private schooling implies that an ever decreasing share of the population earns an ever increasing share of income, private schooling would not be chosen (at least not permanently) given any welfare function that places some weight on group $A$. Indeed, human capital of group $A$ is higher with public education at least during the first five periods.

\section{Conclusions}

The aim of this paper was to examine the merits of private and public schooling within a framework that takes explicit account of the interdependence of education 
and fertility decisions. The analysis leads to three main conclusions. First, we find that public schooling can distort the fertility and education choice of parents, in the sense that parents increase fertility once education is provided for free. In doing so, parents do not internalize the negative effect of having many children on the education resources per child. This effect explains that in a balanced growth path in which there is no inequality, the growth rate of income per capita is higher with private education.

Second, when there is inequality, we find that the comparison of growth rates can switch in favor of public education. The reason is that under private education, parents with below-average income substitute child quantity for quality, and therefore have many children and invest little in education per child. This substitution has a double-negative effect on growth: Children of poor parents have little human capital, and since poor parents have many children, a lot of weight is placed on children with little human capital when computing the average. This differential-fertility effect is not present under public education, since education is free and all parents have the same number of children.

Third, the same differential-fertility effect which lowers growth under private education can also result in a diverging income distribution. Since poor parents have more children than the average, groups with below-average income make up an increasing share of the population over time. If intergenerational persistence in human capital is high, the income of low-skilled groups declines relative to the average. The result is that an ever decreasing fraction of the population accounts for an ever increasing fraction of total income. This divergence can be prevented by a public education system, since fertility and education are equalized across income groups, so that relative group sizes stay the same and incomes converge.

In deriving these results, we use a framework which deliberately downplays the role of fertility differentials, since we assume that skilled and unskilled labor are perfect substitutes in the production function (i.e., production is linear in effective labor supply). If different skills were more complementary (as in a Cobb-Douglas production function using skilled and unskilled labor), changes in the relative number of skilled and unskilled people would have large effects on relative wages. In such a model fertility differentials would have even larger effects on the evolution of the income distribution. Moreover, in concentrating on the role of joint fertility and education 
decisions, our model abstracts from other features which affect the choice of an education regime. For example, a part of the literature argues in favor of education subsidies because of aggregate human capital externalities. If there were an externality from total (as opposed to average) human capital in our model, increased fertility would increase the growth rate. In such a model, public education could lead to higher growth even when there is no inequality.

A robust implication of our analysis is that the merits of different educational systems depend on the initial distribution of income and population. While in this paper we take policies as given, the results indicate that an optimizing policy maker might be expected to switch from one education regime to another as the income distribution evolves over time. The question arises whether the actual history of educational policies in different countries can be explained by a model of political decision making which takes the effects explored in this paper into account. We plan to explore this possibility in further research. 


\section{A Local Stability with Private Education}

Proof of Proposition 1 The set of equations (17) to (20) can be restated as a dynamic system of order two in the variables $\left(\xi_{t}, x_{t}^{A}\right)$ :

$$
\begin{aligned}
\xi_{t+1} & =\frac{x_{t}^{A}\left(\phi\left(1+\xi_{t}\left(1-x_{t}^{A}\right)-\theta\right)\right.}{\left(\phi x_{t}^{A}-\theta\right)\left(1+\xi_{t}\left(1-x_{t}^{A}\right)\right)} \xi_{t}, \\
x_{t+1}^{A} & =\frac{\left(1+\xi_{t+1}\right)\left(x_{t}^{A}\right)^{\tau}\left(\phi x_{t}^{A}-\theta\right)^{\eta}}{\xi_{t+1}\left(x_{t}^{A}\right)^{\tau}\left(\phi x_{t}^{A}-\theta\right)^{\eta}+\left(1+\xi_{t}\left(1-x_{t}^{A}\right)\right)^{\tau}\left(\phi\left(1+\xi_{t}\left(1-x_{t}^{A}\right)\right)-\theta\right)^{\eta}} .
\end{aligned}
$$

The only fixed point of this system is $(\xi, 1)$. Linearizing around this points leads to:

$$
\left[\begin{array}{c}
\xi_{t+1}-\xi \\
x_{t+1}^{A}-1
\end{array}\right]=\left[\begin{array}{cc}
1 & \frac{\theta \xi(1+\xi)}{\theta-\phi} \\
0 & \frac{\theta \tau-(\eta+\tau) \phi}{\theta-\phi}
\end{array}\right]\left[\begin{array}{c}
\xi_{t}-\xi \\
x_{t}^{A}-1
\end{array}\right] .
$$

The linearized dynamics of $x_{t}^{A}$ are autonomous and $x_{t}^{A}$ converges to 1 if $\frac{\theta \tau-(\eta+\tau) \phi}{\theta-\phi}<$ 1 , that is $\tau<1-\frac{\eta \phi}{\phi-\theta}$.

\section{B Global Stability with Public Education}

Proof of Proposition 2 The relative human capital of low-skilled people evolves according to:

$$
x_{t+1}^{A}=\frac{1+\xi_{0}}{\xi_{0}+\left(\frac{1+\xi_{0}}{x_{t}^{A}}-\xi_{0}\right)^{\tau}} \equiv \Phi\left(x_{t}^{A}\right) .
$$

We study the dynamics $x_{t+1}^{A}=\Phi\left(x_{t}^{A}\right)$ in the interval $[0,1]$. There are two fixed fixed points, 0 and 1 . Moreover, the dynamics are monotone:

$$
\Phi^{\prime}\left(x_{t}^{A}\right)=\frac{\tau\left(1+\xi_{0}\right)^{2}\left(\frac{x_{t}^{A}}{1+\xi_{0}\left(1-x_{t}^{A}\right)}\right)^{1-\tau}}{\left(x_{t}^{A} \xi_{0}+\left(x_{t}^{A}\right)^{1-\tau}\left(1+\xi_{0}\left(1-x_{t}^{A}\right)\right)^{\tau}\right)^{2}}>0
$$

$x_{t}^{A}$ thus converges either to 0 or to 1 . The local stability of these two points depends on the derivative of $\Phi$ :

$$
\Phi^{\prime}(0+)=+\infty \quad \Phi^{\prime}(1)=\tau .
$$

Since the fixed point at 0 is locally unstable and the dynamics are monotone, the fixed point at 1 is globally stable. 


\section{References}

Becker, Gary S. and H. Gregg Lewis. 1973. “On the Interaction between the Quantity and Quality of Children." Journal of Political Economy 81:S279-288.

Becker, Gary S., Kevin M. Murphy, and Robert Tamura. 1990. "Human Capital, Fertility, and Economic Growth." Journal of Political Economy 98:12-37.

Bénabou, Roland. 1996a. "Equity and Efficiency in Human Capital Investment: The Local Connection." Review of Economic Studies 63 (2): 237-64.

- 1996b. "Heterogeneity, Stratification, and Growth: Macroeconomic Implications of Community Structure and School Finance." American Economic Review 86 (3): 584-609.

- 1996c. "Inequality and Growth." NBER Macroeconomics Annual, pp. 11-74.

de la Croix, David and Matthias Doepke. 2002. "Inequality and Growth: Why Differential Fertility Matters." Forthcoming, American Economic Review.

de la Croix, David and Philippe Michel. 2002. A Theory of Economic Growth: Dynamics and Policy in Overlapping Generations. Cambridge: Cambridge University Press.

de la Croix, David and Philippe Monfort. 2000. "Education funding and regional convergence." Journal of Population Economics 13 (3): 403-424.

Fernández, Raquel and Richard Rogerson. 1996. "Income Distribution, Communities, and the Quality of Public Education." Quarterly Journal of Economics 111 (1): 135-64.

- 1997. "Keeping People Out: Income Distribution, Zoning, and the Quality of Public Education." International Economic Review 38 (1): 23-42.

—. 1998. "Public Education and Income Distribution: A Dynamic Quantitative Evaluation of Education-Finance Reform." American Economic Review 88 (4): 813 833.

—. 2001. "Sorting and Long-Run Inequality." Quarterly Journal of Economics 116 (4): 1305-41.

Glomm, Gerhard and B. Ravikumar. 1992. "Public Versus Private Investment in Human Capital: Endogenous Growth and Income Inequality." Journal of Political Economy 100 (4): 818-834.

Gokhale, Jagadeesh, Lawrence Kotlikoff, James Sefton, and Martin Weale. 2001. "Simulating the Transmission of Wealth Inequality via Bequests." Journal of Public Economics 79:93-128.

Haveman, Robert and Barbara Wolfe. 1995. “The Determinants of Children's Attainments: A Review of Methods and Findings." Journal of Economic Literature 33 (4): 1829-78. 
Knowles, John. 1999a. "Can Parental Decisions Explain U.S. Income Inequality?" Working Paper, University of Pennsylvania.

-. 1999b. "Social Policy, Equilibrium, Poverty and Investment in Children." Working Paper, University of Pennsylvania.

Kremer, Michael. 1997. “How Much Does Sorting Increase Inequality?" Quarterly Journal of Economics 112 (1): 115-39.

Kremer, Michael and Daniel Chen. 2000. "Income Distribution Dynamics with Endogenous Fertility." NBER Working Paper No. 7530.

Leibowitz, Arleen. 1974. "Home Investments in Children." Journal of Political Economy 82 (2): S111-S131.

Mare, Robert D. 1997. “Differential Fertility, Intergenerational Educational Mobility, and Racial Inequality." Social Science Research 26:263-291.

Preston, Samuel H. and Cameron Campbell. 1993. "Differential Fertility and the Distribution of Traits: The Case of IQ." American Journal of Sociology 98 (5): 9971019.

Rosenzweig, Mark R. and Kenneth I. Wolpin. 1994. "Are There Increasing Returns to the Intergenerational Production of Human Capital? Maternal Schooling and Child Intellectual Achievement." Journal of Human Resources 29 (2): 670-93.

Tamura, Robert. 1991. "Income Convergence in an Endogenous Growth Model." Journal of Political Economy 99 (3): 522-40.

- 1994. "Fertility, Human Capital, and the Wealth of Families." Economic Theory 4 (4): 593-603.

—. 2001. "Teachers, Growth and Convergence." Journal of Political Economy 109 (5): 1021-1059.

U.S. Department of Education. 1998. Digest of Education Statistics. Washington, D.C.: U.S. Department of Education. 